\title{
Gas-Phase Scrambling of Disulfide Bonds during Matrix-Assisted Laser Desorption/ Ionization Mass Spectrometry Analysis
}

\author{
Liang Zhao, ${ }^{\text {a }}$ Ruben T. Almaraz, ${ }^{\mathrm{b}}$ Fan Xiang, ${ }^{\mathrm{c}}$ Jerry L. Hedrick, ${ }^{\mathrm{b}}$ and \\ Andreas H. Franz ${ }^{a}$ \\ ${ }^{a}$ Department of Chemistry, University of the Pacific, Stockton, California, USA \\ ${ }^{\mathrm{b}}$ Department of Animal Science, University of California Davis, Davis, California, USA \\ c Shimadzu Biotech Corporation, Pleasanton, California, USA
}

\begin{abstract}
Evidence for photo-induced radical disulfide bond scrambling in the gas phase during matrix-assisted laser desorption/ionization mass spectrometry (MALDI-MS) is described. The phenomenon was observed during the analysis of tryptic peptides from insulin and was confirmed in the determination of disulfide bonds in the rhamnose-binding lectin SEL24K from the Chinook salmon Oncorhynchus tshawytscha. A possible mechanism for this surprising scrambling is proposed. Despite this finding, the disulfide bond pattern in SEL24K was assigned unambiguously by a multi-enzyme digestion strategy in combination with MALDI mass spectrometry. The pattern was found to be symmetrical in the tandem repeat sequence of SEL24K. To the best of our knowledge, this is the first report of disulfide bond scrambling in the gas phase during MALDI-MS analysis. This observation has important ramifications for unambiguous assignment of disulfide bonds. (J Am Soc Mass Spectrom 2009, 20, 1603-1616) (C) 2009 American Society for Mass Spectrometry
\end{abstract}

$\mathrm{D}$ isulfide bonds, among the most common posttranslational modifications (PTMs), play a critical role in establishing and stabilizing the three-dimensional structure of proteins. The assignment of disulfide bonds can contribute to the understanding of biological function of proteins. However, unambiguous assignment of disulfide bonds is far from trivial and still presents a challenge to analytical chemists [1-3]. The most common complication encountered is solution-phase disulfide bond scrambling that changes the original disulfide bond pattern and results in erroneous data. Typically, the scrambling occurs during enzymatic digestion of the protein if the $\mathrm{pH}$ is too high $(\mathrm{pH}>8)$. Hydroxide ions in aqueous solution act as external nucleophiles and cause the formation of thiolate anions, which in turn act as peptide-internal nucleophiles on neighboring S-S-bonds. The scrambling mechanism has been reviewed [4-6].

The techniques used to analyze disulfide bond patterns have improved dramatically since the development of matrix-assisted laser desorption/ionization (MALDI) and electrospray ionization (ESI). In combination with enzymatic digestions, chemical modifications, and separation by high-performance liquid chromatography (HPLC), MALDI and ESI have been widely used in protein sequencing and disulfide mapping [7-11].

Address reprint requests to Dr. A. H. Franz, Department of Chemistry, University of the Pacific, 3601 Pacific Ave., Stockton, CA 95211, USA. E-mail: afranz@pacific.edu
Disulfide-bonded peptides from ESI have been sequenced by collisionally-activated dissociation (CAD). Fragmentation across the S-S-bond (homolytic and heterolytic) provides evidence for the structure $[12,13]$. Among other feasible fragmentation mechanisms, one paper has reported evidence for disulfide scrambling in the gas phase during CAD [14]. A free thiol-containing antibiotic metabolite, desfuroylceftiofur (DFC), was used to derivatize peptides into disulfide-linked bioactive compounds. The MS/MS analysis of one derivative, [vasopressin(SS-DFC) $\left.{ }_{2}+\mathrm{H}\right]^{+}$by CAD resulted in loss of one and two DFC moieties through either homolytic or heterolytic dissociation of the disulfide bonds, including hydrogen migration in the latter case. In contrast, the homolytic cleavage resulted in the formation of an odd-electron product ion and a neutral fragment. In addition, it was observed that the loss of two DFC moieties from this complex resulted in an intramolecular disulfide bond in the peptide chain. CAD transfers energy through multiple collisions and may give rise to such rearrangements.

MALDI, on the other hand provides energy through laser light; however, the ionization process for MALDI-MS is still not fully understood. During the MALDI analysis, analyte and matrix molecules are desorbed and ionized upon UV laser excitation. In the ion source, gas-phase reactions, such as redox reactions, may occur between the electronically excited analyte ions and matrix ions/molecules. For example, the mechanism of the reduction of $\mathrm{Cu}$ (II) to $\mathrm{Cu}$ (I) in 
MALDI was studied, and it was found that this reduction was caused by gas-phase charge exchange with matrix molecules, which is a thermodynamically favorable process [15]. Recently, studies of a MALDI insource photo-oxidation reaction have shown that on a photoelectrode-modified target plate, hydroquinone can be photo-oxidized to benzoquinone by UV laser excitation [16]. This reaction in turn can be used for covalent labeling of cysteine-containing peptides. Fukuyama et al. described an effective method to sequence and locate disulfide bonds of peptides with the help of a reductive matrix [7]. During the MALDI MS analysis of disulfide bond-containing proteins, ions with intact as well as cleaved disulfide bonds have been detected, and the terminus on the half-cysteine residues was thought to be an odd-electron sulfhydryl ion. It is now well-established that the MALDI plume provides favorable conditions for gas-phase reactions. Therefore, the plume may be the source of radical species responsible for the scrambling of disulfide bonds in tryptic peptides from the salmon lectin SEL24K, as we report it here.

SEL24K is a rhamnose-binding lectin isolated from the egg of the Chinook salmon Oncorhynchus tshaw$y$ tscha. There is mounting evidence that this SEL24K lectin provides a block to polyspermy upon fertilization via binding to glycoprotein ligands in the egg jelly. SEL24K has 195 amino acids, including 16 cysteines with completely conserved locations, in comparison with the analogous galactose-specific lectin (SUEL) from the sea urchin egg Anthocidaris crassipina [17].

In this paper, we present evidence for photo-induced disulfide bond scrambling in the gas phase during MALDI- time-of-flight (TOF) analysis of tryptic peptides of SEL24K. A possible mechanism for this scrambling is proposed. To the best of our knowledge, this is the first report of disulfide bond scrambling in the gas phase during MALDI-MS analysis. However, the disulfide bond pattern in SEL24K was established unequivocally by applying a multi-enzyme strategy in combination with MALDI-TOF MS/MS analysis.

\section{Experimental}

\section{Materials}

Chinook salmon Oncorhynchus tshawytscha eggs were obtained from the Nimbus Dam Fish Hatchery, California Department of Fish and Game, Sacramento, CA, USA. The immobilized L-1-tosylamido-2-phenylethylchloromethyl ketone (TPCK) trypsin was purchased from Pierce (Rockford, IL, USA). Endoproteinase Asp-N from Pseudomonas fragi mutant strain (proteomics grade), endoproteinase Glu-C from Staphylococcus aureus V8 ${ }^{\circ}$ (proteomics grade), $\alpha$-cyano-4-hydroxycinnamic acid (CHCA), 2, 5-dihydroxybenzoic acid (2,5-DHB), sinapinic acid (SA), 2,4,6-trihydroxyacetophenone (THAP), $\mathrm{MeCN}$ (HPLC grade), and trifluoroacetic acid (TFA) were purchased from Sigma-Aldrich (St. Louis, MO, USA).

\section{Purification of SEL24K}

SEL24K was isolated according to a previously published method [18]. Further purification was performed on a SCL-10A VP liquid chromatograph (Shimadzu, Columbia, MD, USA) with a 208TP C8 reversed-phase column (particle size $5 \mu \mathrm{m}, 300 \mathrm{~A}, 4.6 \times 250 \mathrm{~mm}$; Dionex, Sunnyvale, CA, USA). The total running time was $95 \mathrm{~min}$ at a flow rate of $0.5 \mathrm{~mL} / \mathrm{min}$ with a binary gradient starting isocratically with Solvent A $(0.1 \%$ TFA in water) for $10 \mathrm{~min}$. Subsequently, Solvent B (0.1\% TFA in acetonitrile) was increased to $25 \%$ within the next 4 min, then was increased to $35 \%$ within the following 26 min, and finally was increased to $70 \%$ over the next $40 \mathrm{~min}$. After reaching $70 \%$, the solvent was run isocratically for another $10 \mathrm{~min}$ and ramped back to Solvent A over the last $5 \mathrm{~min}$.

\section{Enzymatic Digestion of SEL24K}

To get unequivocal assignment of all disulfide bondcontaining peptides, different types of enzymatic digestions were performed. We used three different enzymes and several enzyme combinations as described below. All digestions were carried out at $37^{\circ} \mathrm{C}$ over $16-18 \mathrm{~h}$ for each enzyme unless stated differently.

Native SEL24K (0.1-0.5 mg) was denatured (8 M urea, $37^{\circ} \mathrm{C}$ for $30 \mathrm{~min}$ ). Immobilized TPCK trypsin on cross-linked $4 \%$ beaded agarose $(50 \mu \mathrm{L})$ was washed with digestion buffer $\left(25 \mathrm{mM} \mathrm{NH} \mathrm{HCO}_{3}, \mathrm{pH} 7.8,3 \times\right.$ $200 \mu \mathrm{L})$. The immobilized TPCK trypsin was suspended in the digestion buffer $(100 \mu \mathrm{L})$ and was added into the SEL24K sample. The reaction mixture was incubated in a rapidly shaking water bath.

SEL24K was digested with endoproteinase Asp-N $(\mathrm{E} / \mathrm{S}=1: 20-1: 100)$ in $25 \mathrm{mM} \mathrm{NH}_{4} \mathrm{HCO}_{3}$ buffer (pH 7.8).

SEL24K was digested with endoproteinase Glu-C $(\mathrm{E} / \mathrm{S}=1: 20-1: 100)$ in $100 \mathrm{mM}$ phosphate buffer $(\mathrm{pH}$ 7.8).

SEL24K was initially digested with immobilized TPCK trypsin (25 mM NH$\left.{ }_{4} \mathrm{HCO}_{3}, \mathrm{pH} 7.8\right)$. The trypsin gel was separated from the digestion mixture by centrifugation and the mixture was further digested with Asp $-N$ in the same buffer.

SEL24K was initially digested with immobilized TPCK trypsin (100 mM phosphate buffer, $\mathrm{pH} 7.8$ ). The trypsin gel was separated by centrifugation, and the mixture was further digested with $G l u-C$ in the same buffer.

\section{Sample Preparation and MALDI MS Analysis}

The dried-droplet method was used. The sample solution $(1 \mu \mathrm{L})$ was mixed with matrix solution $(1 \mu \mathrm{L}$, saturated CHCA solution in $50 \% \mathrm{MeCN}$ in $0.1 \%$ TFA; or saturated SA solution in $50 \% \mathrm{MeCN}$ in $0.1 \%$ TFA; or 3 
$\mathrm{mg} / 100 \mu \mathrm{L} 2,5-\mathrm{DHB}$ in $50 \% \mathrm{EtOH}$ in $0.1 \%$ TFA; or 3 $\mathrm{mg} / 100 \mu \mathrm{L}$ THAP in $50 \% \mathrm{MeCN}$ ) on the MALDI-plate. External calibration of MALDI mass spectra was carried out with the ProteoMass MALDI calibration kit (SigmaAldrich, St. Louis, MO, USA). C18 ZipTips were used to desalt and concentrate the samples before MALDI-TOF MS analysis. MALDI and MALDI-CAD spectra were recorded in positive reflectron mode on an AXIMA curved-field reflectron (CFR) MALDI-TOF mass spectrometer and on a quadrupole ion-trap (QIT) MALDITOF instrument (Kratos/Shimadzu, Columbia, MD, USA).

\section{Results and Discussion}

\section{Gas-Phase Scrambling of Disulfide Bonds}

The UV-laser-induced fragmentation of S-S-bonds during MALDI is a process that proceeds with high probability through radical intermediates. For example, the solution-phase oxidation of hydroquinone to benzoquinone is known to proceed through the resonantlystabilized semiquinone radical intermediate (Scheme 1a).

This process furnishes two protons and two electrons, the equivalent of a hydrogen molecule, and has been used for the one-electron reduction of photo- sensitized AgBr salts in black-and-white photography in the past. It is also the basis for the radical scavenging abilities of many natural products [19-21]. The hydroquinone moiety is also present in the widely-used 2,5-DHB and, very recently, a method for photoinduced redox tagging of cysteine sulfhydryls with benzoquinone has been described (Scheme 1b) [16]. The hydroquinone system appears to get oxidized more easily if electron-donating substituents $(\mathrm{R}=\mathrm{OMe})$ as opposed to electron-withdrawing substituents $(\mathrm{R}=$ $\mathrm{COOH})$ are present. Nevertheless, MALDI matrices such as 2,5-DHB with $\mathrm{OH}$-groups in para-position relative to each other have the potential to undergo such redox reactions as well (Scheme 1c). Analogously, two equivalents of $\alpha$-cyano-4-hydroxycinnamic acid (CHCA) can possibly be converted by laser irradiation to resonantly-stabilized phenoxy radicals and two protons and two electrons, i.e., " $\mathrm{H}_{2}$ " (Scheme 1d). Experimentally, we were able to demonstrate that there is evidence for dimeric matrix-analyte complexes $[\mathrm{M}+$ $2 \mathrm{CHCA}+\mathrm{H}^{+}$setting the stage for reduction of suitable substrates $\mathrm{M}$.

When analyzing cysteine, we observed protonated dimeric and trimeric CHCA species alone at $m / z 378.9$ and 568.6, respectively, and the $\left[\mathrm{M}+2 \mathrm{CHCA}-\mathrm{H}_{2} \mathrm{O}+\right.$

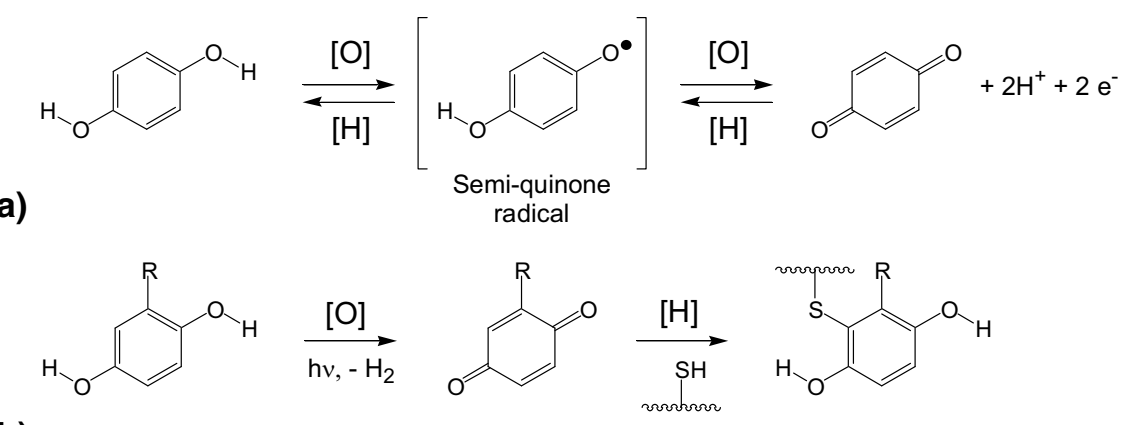

(b) $\mathrm{R}=\mathrm{COOH}, \mathrm{H}, \mathrm{OMe}$

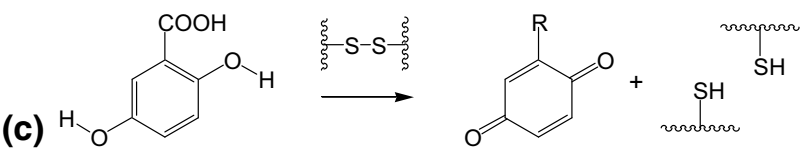

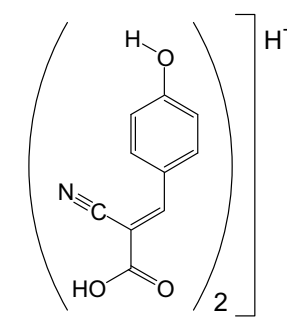

(d) $m / z 379.06$

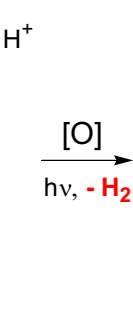

$\underset{v,-\mathrm{H}_{2}}{\stackrel{[\mathrm{O}]}{\longrightarrow}}$

$$
\mathrm{m}
$$

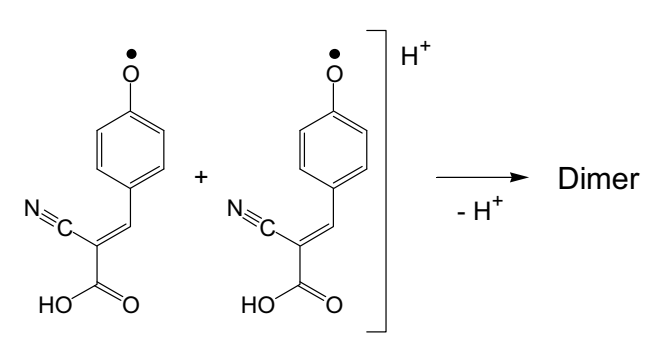

Scheme 1. (a) Two-electron oxidation of hydroquinone to benzoquinone through a semiquinone radical intermediate used, e.g., in black-white photography to reduce photo-sensitized silver salts; (b) photo-redox labeling of sulfhydryl group with 2-substituted hydroquinone-derived matrix molecules upon laser irradiation as published recently [16]; (c) process of laser-induced redox in-source dissociation (ISD) of disulfide bonds; (d) proposed laser-induced formation of a resonancestabilized protonated radical from CHCA and subsequent formation of a neutral dimer. 

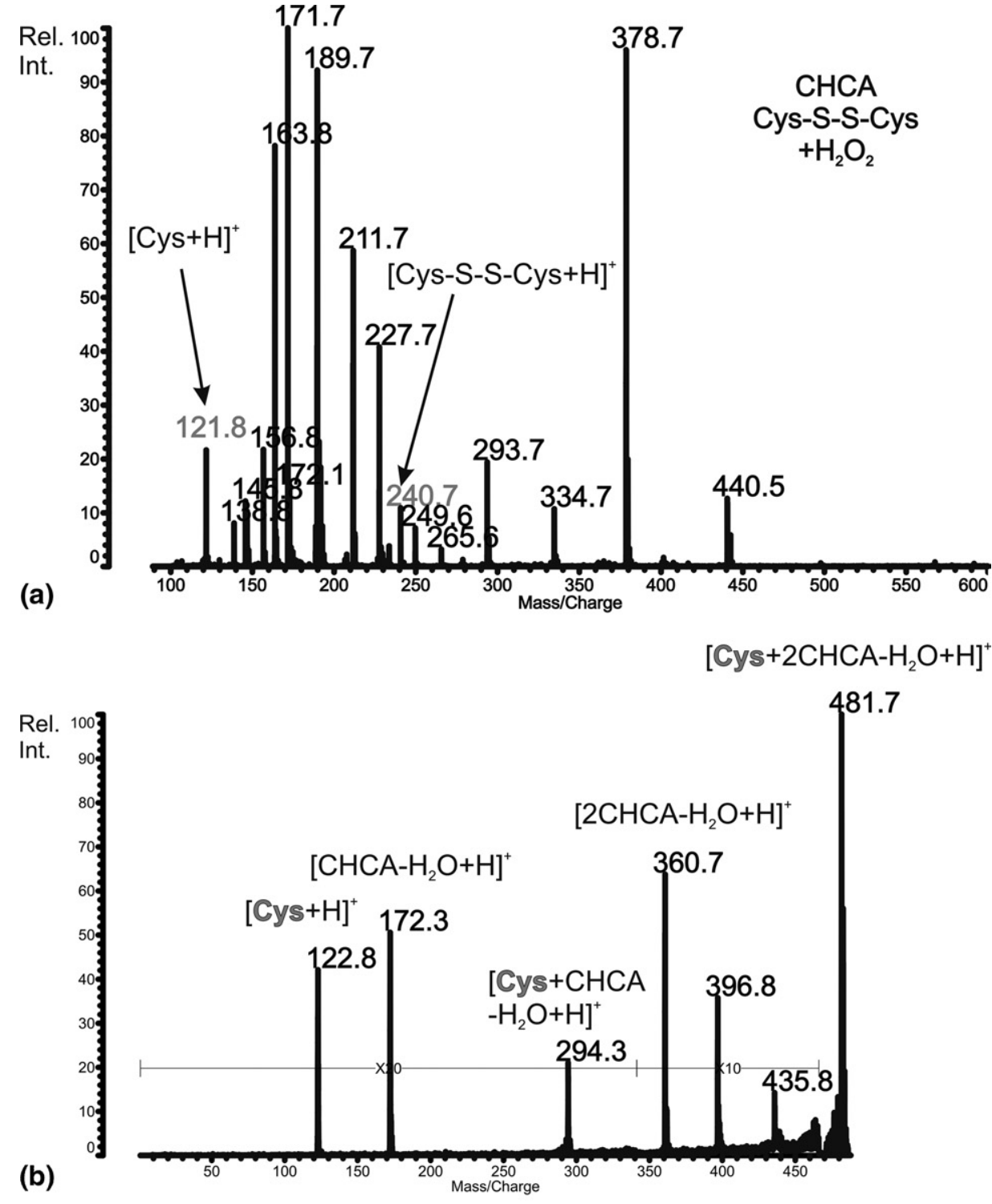

(b)

$[3 \mathrm{CHCA}+\mathrm{H}]^{+}$
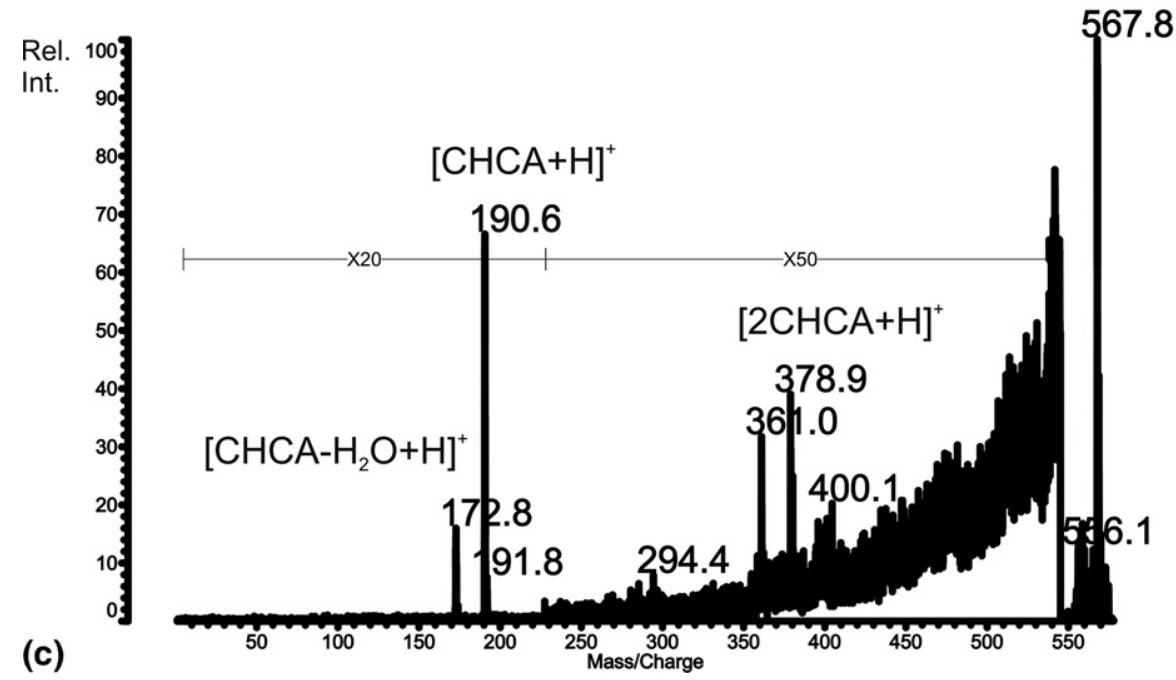
$\mathrm{H}^{+}$complex at $m / z 481.9$ (Figure 1a). Interestingly, the $[\mathrm{M}+2 \mathrm{CHCA}+\mathrm{H}]^{+}$complex at $\mathrm{m} / \mathrm{z} 499.9$ was essentially absent. After isolation of the ion $\mathrm{m} / \mathrm{z} 481.9$, postsource decay (PSD) fragmentation showed the loss of intact protonated L-cysteine at $m / z 122.8$ (Figure 1b). The presence of anhydride species was supported by the observation of a peak at $m / z$ 360.7, representing a $\left[2 \mathrm{CHCA}-\mathrm{H}_{2} \mathrm{O}+\mathrm{H}\right]^{+}$species, a peak at $m / z 172.3$ for the acylium ion of CHCA, and a peak at $m / z 294.3$ indicating a $\left[\mathrm{M}+\mathrm{CHCA}-\mathrm{H}_{2} \mathrm{O}+\mathrm{H}\right]^{+}$ion. The acylium ion of CHCA has much more pronounced resonance stabilization compared with the acylium ion from cysteine. Therefore, the latter was not observed at $\mathrm{m} / \mathrm{z} 104$. The existence of a noncovalent protonated CHCA trimer could be established after isolation and PSD fragmentation of the ion at $m / z 567.8$ (Figure 1c). Already at very low laser power setting, fragmentation resulted in ions for the protonated dimer at $\mathrm{m} / \mathrm{z} 378.9$ (dehydrated at $\mathrm{m} / \mathrm{z} 361$ ) and for the protonated monomer at $m / z 190.6$ (dehydrated at $m / z$ 172.8), respectively. Analogous dimeric species in 2,5-DHB and THAP were not observed.

With good evidence for dimeric matrix complexes with protonated analyte molecules, we investigated the behavior of cystine. To ascertain the complete oxidation of cystine, samples were prepared after incubation with $\mathrm{H}_{2} \mathrm{O}_{2}(3 \%)$. As expected, cystine underwent significant reductive fragmentation in either $\mathrm{CHCA}$ or $2,5-\mathrm{DHB}$ matrix during desorption/ionization (Figure 2a, b). When we changed the matrix to THAP as a control experiment, no reductive fragmentation was observed, and only the $[\mathrm{M}+\mathrm{H}]^{+}$species for cystine was observed at $m / z 240.7$ (Figure 2c). THAP has three $\mathrm{OH}$-groups in meta-position relative to each other and, therefore, does not undergo redox reactions easily.

Next, we turned to bovine insulin as a simple model protein. Bovine insulin consists of two peptide chains referred to as A- and B-chain containing a total of three disulfide bonds (two interdisulfide bonds one intradisulfide bond, Figure 3a). Because there are only two trypsin processing sites $\left(\mathrm{R}_{\mathrm{B} 22}, \mathrm{~K}_{\mathrm{B} 29}\right)$, the digest contained one peptide with all three S-S-bonds intact. We found trypsin digestion of insulin helpful because it resulted in better mass spectral response than native insulin. Out of four matrices (CHCA, 2,5-DHB, SA and THAP), only CHCA and SA resulted in good spectral response, whereas 2,5-DHB and THAP did not give enough identifiable signals at high mass range. The spectra obtained from MALDI-TOF and MALDI-QITTOF with CHCA as matrix showed two major fragment ions I and II at $m / z 4821.8$ and 859.3, respectively, both of which were assigned as shown (Figure $3 b$ ). The less intensive peak at $\mathrm{m} / \mathrm{z} 2485.6$ was assigned to the B-chain fragment IV with newly formed intradisulfide bond. Whereas conventional reductive in-source dissociation (ISD) would lead to a pair of reduced cysteines and an A-chain fragment ion III with a theoretical $\mathrm{m} / \mathrm{z}$ value of 2336.9, no evidence for this peptide was observed. However, we observed the oxidized A-chain fragment ion III at $m / z 2335.1$ in significant abundance when we switched the matrix to SA (Figure 3c). A possible explanation may be the extent of peptide protonation before desorption inside the matrix. In CHCA, the process appears to favor the most basic peptides. However, in SA, larger peptides and neutral or moderately basic peptides are ionized as well, which may reflect a difference in the efficiency of light-absorption in the matrix and a difference in the subsequent physical desorption/ionization process. This would be consistent with the notion that the A-chain fragment ion III lacks arginine and lysine. Disulfide scrambling may be explained by the mechanism shown in Figure 3a. The observed fragment ion IV is the consequence of photoinitiated formation of four sulfhydryl radicals and rapid intramolecular recombination, a nonreductive process consistent with previously published results from CAD experiments [14].

The peptide at $m / z 2485.6$ was submitted subsequently to an MS/MS experiment (Figure 4a). A number of $b$ and $y$-type ions (e.g., $b_{5}, b_{6}$ and $b_{19}-b_{21} ; y_{16}-y_{18}$ ) from outside the disulfide loop were observed (Figure 4b). The singly-charged "triplet" ions at $m / z 989.7$ (base peak), 1023.7, and 1055.7 separated by 34 and $32 \mathrm{~m} / \mathrm{z}$, respectively, indicated asymmetric cleavage across the disulfide bond. Fragment ions originating from the cleavage of amide bonds within the intrachain disulfide loop were assigned as shown in Figure $4 \mathrm{~b}$. These fragment ions exhibited a mass shift of $+32 \mathrm{~m} / \mathrm{z}$ or -34 $\mathrm{m} / \mathrm{z}$ compared with the predicted $\mathrm{m} / \mathrm{z}$ values for the fully reduced $b$ or $y$-type ions. A salt bridge mechanism has been proposed previously to explain the disulfide bond cleavage in protonated peptides under lowenergy CAD condition [13]. The same theory was used to explain the fragmentation of intrachain disulfide bonds of peptides by nanoESI CAD and to extend it to a proton-induced asymmetric cleavage of the disulfide bond [22]. Such fragmentations were shown to yield a modified cysteine with a disulfhydryl substituent and a dehydroalanine residue on the $C-S$ cleavage site. The subsequent amide bond fragmentation consequently resulted in a series of $b$ - and y-type ions with the respective mass shift.

Figure 1. MS-data collected on AXIMA-CFR MALDI-TOF instrument: (a) mass spectrum of L-cysteine (CHCA matrix). Peaks for protonated matrix molecules, dimers, and trimers are visible. The protonated matrix molecule can lose water to form an acylium cation at $\mathrm{m} / \mathrm{z} 171.8$; (b) PSD spectrum of the complex [L-Cys $\left.+2 \mathrm{CHCA}-\mathrm{H}_{2} \mathrm{O}+\mathrm{H}\right]^{+}$; (c) PSD spectrum of the protonated noncovalent trimeric matrix cluster at $\mathrm{m} / \mathrm{z}$ 568.0. The cluster fragmented already at very low laser energy. 

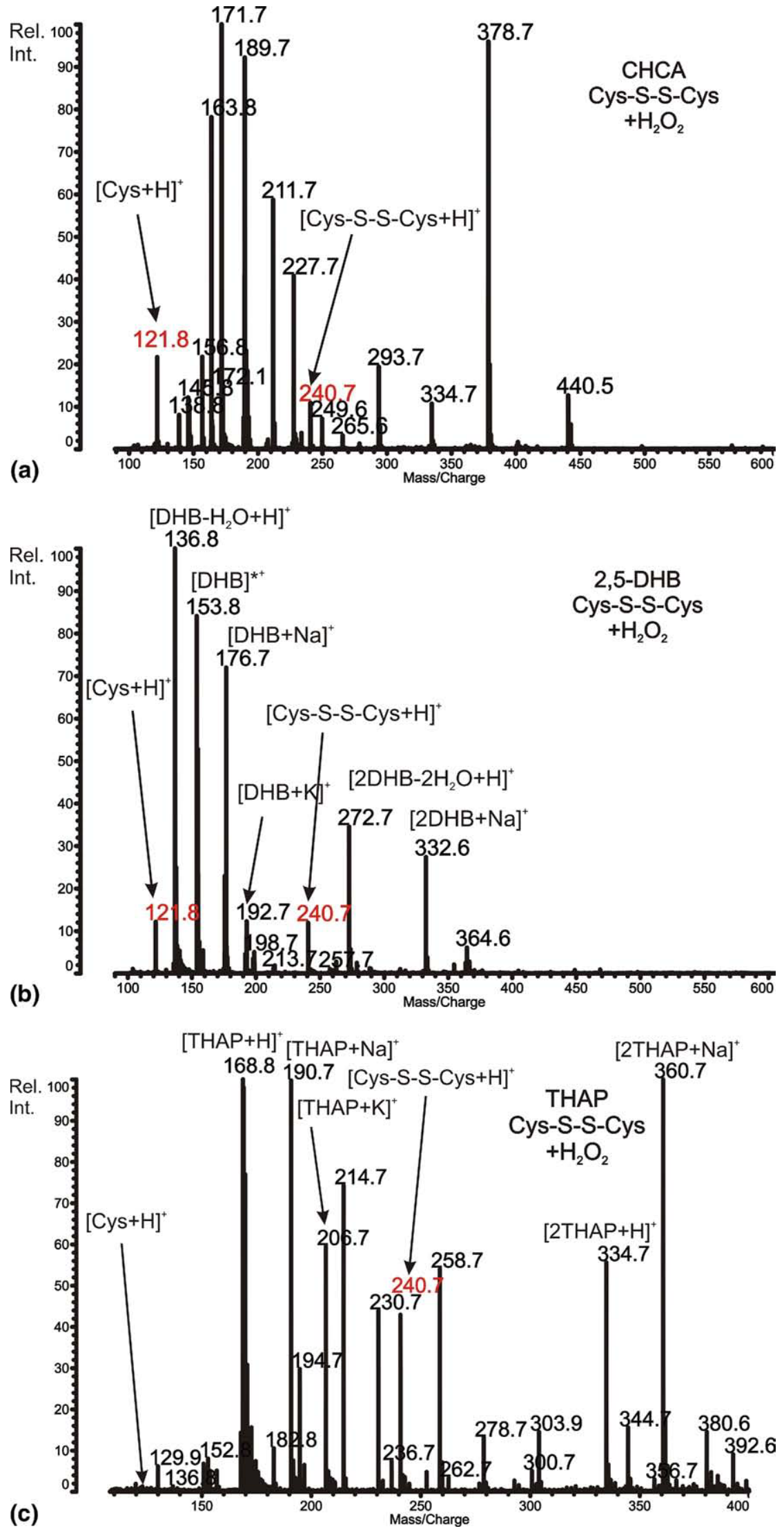

Figure 2. MS-data collected on AXIMA-CFR MALDI-TOF instrument: (a) mass spectrum of cystine (CHCA matrix) with ISD ions clearly visible; (b) mass spectrum of cystine (2,5-DHB matrix) with ISD ions clearly visible; (c) Absence of ISD ions during ionization from THAP. 


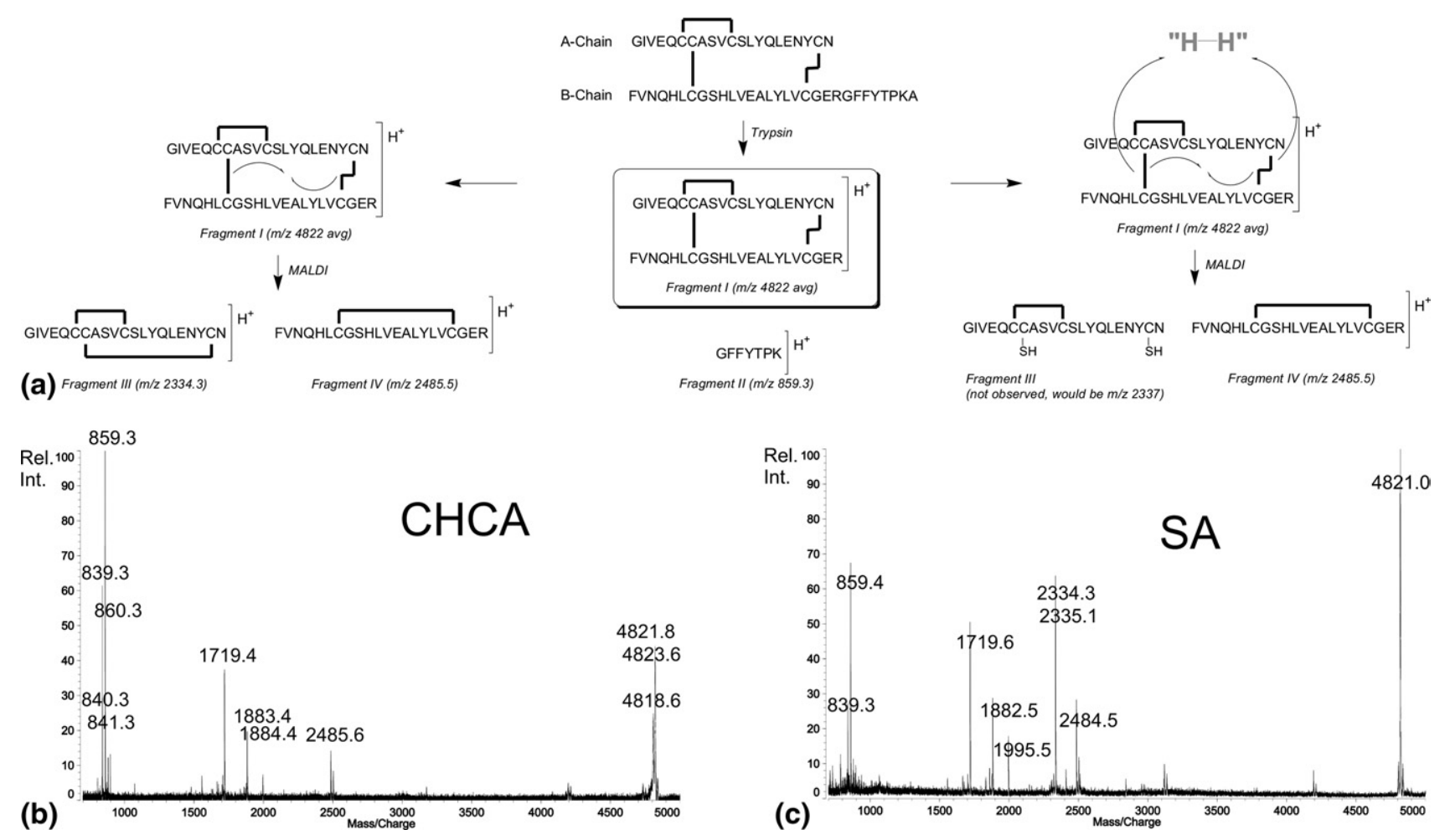

Figure 3. MS-data collected on both AXIMA-CFR MALDI-TOF and QIT-TOF instrument: Mass spectrum of trypsinized bovine insulin. The signal at $\mathrm{m} / \mathrm{z} 2485.6$ corresponds to a new peptide (IV) with an intrachain disulfide bond. The accuracy of the mass was independently ascertained on both instruments. A possible mechanism for this gas-phase disulfide bond scrambling is based on reduction by the matrix during desorption/ionization (right) or photo-induced disulfide scrambling (left). Evidence for the latter was observed from fragment III in SA.

Both the insulin sample and the SEL24K sample were digested with trypsin according to the same procedure. We used electrospray (TSQ Quantum Triple Quadrupole MS; Thermo Scientific, Waltham, MA, USA) as a different ionization technique to show that basecatalyzed disulfide scrambling in solution did not contribute in our case. The singly-charged fragment ion II was observed at $\mathrm{m} / \mathrm{z} 859.5$ as well as the doubly-, triply-, and quadruply-charged species of fragment ion I at $\mathrm{m} / \mathrm{z}$ $2410.9,1607.6$, and 1205.9, respectively, (see Supplemental Materials, which can be found in the electronic version of this article). Analogous results were also obtained with an LC1200L Triple Quadrupole ESI-MS (Varian, Palo Alto, CA, USA) (data not shown). In either case, no peptide ions with scrambled disulfide bonds were observed, which indicated that the disulfide scrambling reported here is prone to occur in the gas phase of the MALDI ionization source.

An analogous S-S-bond scrambling reaction in the gas phase was observed during MALDI analysis of tryptic peptides from the salmon egg lectin SEL24K. First, we established the correct disulfide bond pattern in SEL24K and subsequently investigated the newly formed peptides with scrambled disulfide bonds as discussed below.

\section{Purification of SEL24K}

Previously isolated and stored (frozen) SEL24K protein was purified a second time using HPLC to obtain protein of the highest purity for enzymatic digestion. SEL24K can be stored at $-20^{\circ} \mathrm{C}$ for several months with only minor degradation as indicated by the unidentified compounds eluting at 6, 33, and $75 \mathrm{~min}$ (see Supplemental materials). SEL24K has a theoretical molecular mass of 21,503 Da, as confirmed by MALDI-TOF analysis from SA. After spectral smoothing, signals for the $[\mathrm{M}+\mathrm{H}]^{+}$and the $[\mathrm{M}+2 \mathrm{H}]^{2+}$ species at $m / z 21,500$ and 10,900 were observed, respectively, in accordance with previous reports and with the $c$ DNA sequence (see Supplemental Materials).

\section{Enzymatic Digestions of SEL24K}

The strategy of S-S-bond elucidation was based on the use of multiple digestion approaches. With this approach, multiple peptide pools were generated for identification of the disulfide bond pattern. The advantage of this approach was that certain peptides that were suppressed during MALDI analysis in one digest were readily identified in another digest. Ion suppres- 

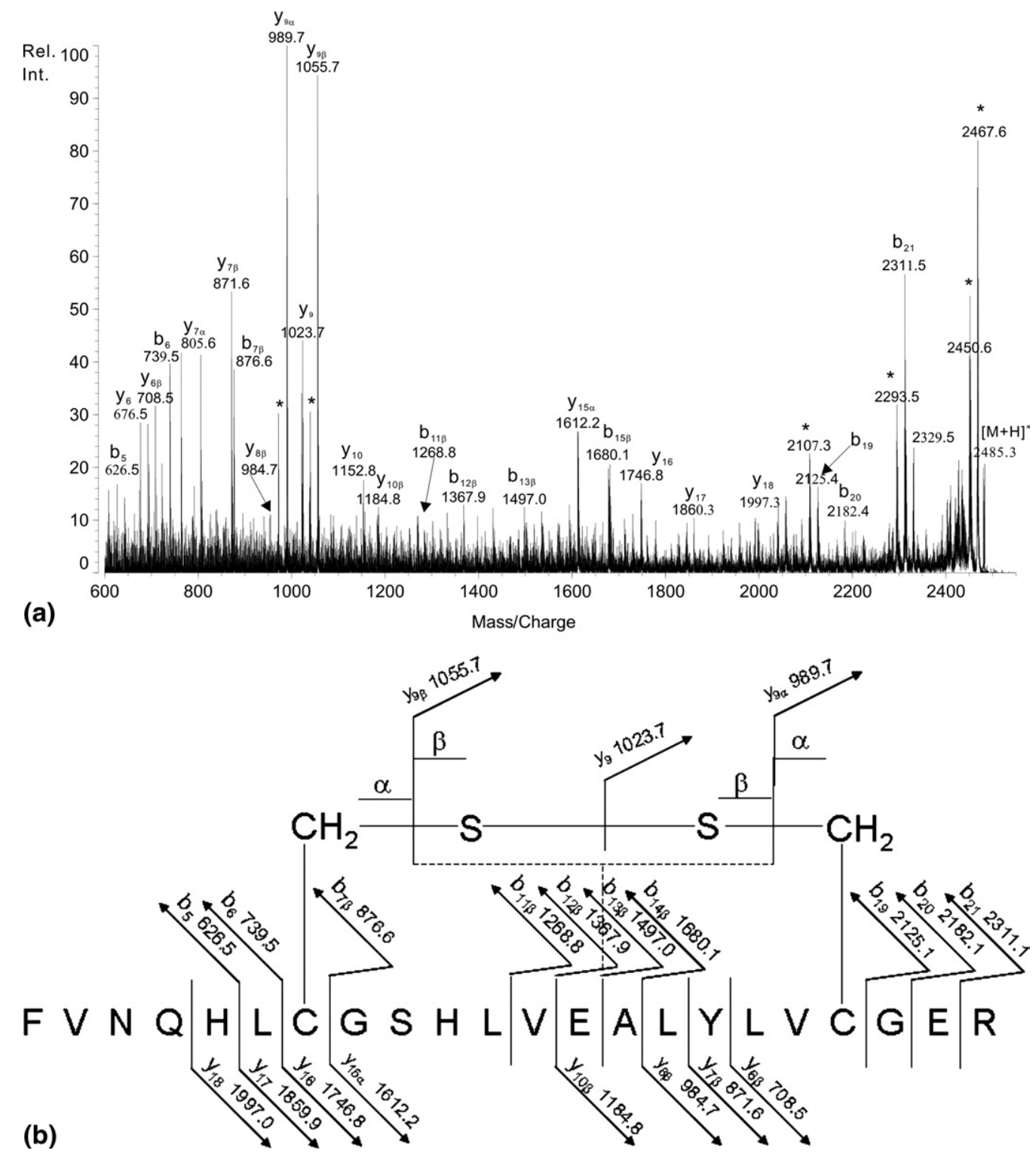

Figure 4. MS-data collected on the MALDI-QIT-TOF instrument: (a) MS/MS spectrum of intrachain disulfide bond-containing peptide ion at $\mathrm{m} / \mathrm{z} 2485.6$ derived from gas-phase scrambling during MALDI; (b) Assignment of the MS/MS fragmentation of the ion from a). Internal losses are indicated by an asterisk.

sion effects are primarily based upon the basicity of the peptide and its success in competing for the proton. If the peptide contains one or several basic amino acids, it can be detected in most cases with reasonable abundance during concurrent ionization of a peptide mixture. A particular enzyme might yield peptides that do not contain any basic amino acids. Such peptides could be present but completely suppressed and not observed. However, an alternative enzyme digestion might produce a similar amino acid sequence including a basic amino acid, which leads to successful ionization and detection.

\section{Assignment of the Disulfide Bond Pattern in SEL24K}

The mass spectrometric analysis of the different peptide pools resulted in multiple characteristic signals for peptide fragments and disulfide-bonded peptides in each case. The former could be identified from theoretical peptide masses of in silico digestions (e.g., ProteinProspector), whereas the latter were identified from empirical combinations of peptides and experimental $\mathrm{m} / \mathrm{z}$ values of the corresponding S-S-bonded peptides including their reduced ISD-fragments. For example, the digestion of SEL24K with Glu-C yielded a different peptide pool (see Supplemental Materials). The use of different matrices for MALDI analysis resulted in markedly different spectra. Much more extensive fragmentation was observed from CHCA as opposed to SA. However, in SA, one ISD-fragment ion for the protonated $C^{15} / C^{94}$-linked peptide was observed at $\mathrm{m} / \mathrm{z}$ 1212.2, whereas it was absent in the spectrum from CHCA. The signal at $\mathrm{m} / \mathrm{z} 2883.7 \mathrm{rep}-$ 
Table 1. Observed $m / z$ values of $[\mathrm{M}+\mathrm{H}]^{+}$peptides in MALDI-TOF spectra. The matrix used was CHCA unless indicated otherwise

\begin{tabular}{|c|c|c|c|c|c|}
\hline & Peptide & Digest & $\begin{array}{c}m / z \\
{[\mathrm{M}+\mathrm{H}]^{+} \text {theor }}\end{array}$ & $\begin{array}{c}m / z \\
{[\mathrm{M}+\mathrm{H}]^{+} \text {obs }}\end{array}$ & $\begin{array}{c}m / z \\
(I S D)\end{array}$ \\
\hline 1 & $\left.\right|_{\text {DVC }} ^{\text {AISITC }}{ }^{35}$ SIGRPDNQLT & $\begin{array}{l}\text { a) Asp-N } \\
\text { b) TPCK trypsin/Asp-N }\end{array}$ & 2295.1 & $2295.4( \pm 0.5)$ & 1417.8 \\
\hline 2 & $\begin{array}{l}\text { AISITC }^{6} \text { EGS } \\
\text { QHDVC }^{35} \text { SIGRP }\end{array}$ & TPCK trypsin/Asp-N & 1988.9 & $1988.2( \pm 0.5)$ & \\
\hline 3 & $\begin{array}{l}\text { GSDALLQC }^{15} \mathrm{D} \\
\text { TKYSC }_{94}^{94} \text { VQQQE }\end{array}$ & Glu-C & 2131.9 & $2132.7( \pm 0.5)$ & 1212.2 \\
\hline 4 & $\begin{array}{l}\mathrm{YSC}^{94} \text { VQQQETISSIIC } \\
\qquad \text { DVC }^{106} \text { EGS } \\
\end{array}$ & TPCK trypsin/Asp-N & 3453.7 & $3455.5( \pm 1.5)$ & 1480.9 \\
\hline 5 & $\left.\right|_{V G} ^{\text {TISSIIS }^{106} \mathrm{E}}$ & TPCK trypsin/Glu-C & 2228.1 & $2228.7( \pm 0.5)$ & 1365.6 \\
\hline 6 & $\begin{array}{l}\text { TISSIIC }_{\mid}^{106} \mathrm{E} \\
\text { qHDVC }^{135} \text { SIGRPHQQLK }\end{array}$ & TPCK trypsin/Glu-C & 2591.2 & $2591.7( \pm 0.5)$ & 1728.6 \\
\hline 7 & $\begin{array}{l}\text { TISSIIC }_{\mid}^{106} \mathrm{E} \\
\text { QHDVC }^{135} \text { SIGRPHQQLK }\end{array}$ & TPCK trypsin/Glu-C & 2608.2 & $2609.0( \pm 0.5)$ & 1745.6 \\
\hline 8 & $\left.\right|_{\text {YLDVAYTC }} ^{\text {SQLLC }}{ }^{115} \mathrm{DR}$ & TPCK trypsin/Glu-C & 1893.8 & $1893.5( \pm 0.5)$ & 834.3 \\
\hline 9 & $\underbrace{\mathrm{C}^{162} \mathrm{DGKRQC}} \mathrm{J}^{168 \mathrm{IVK}}$ & TPCK trypsin & 1147.6 & $1147.8( \pm 0.5)$ & \\
\hline 10 & 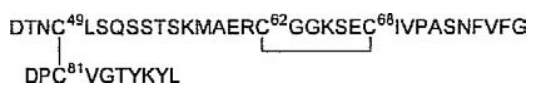 & Asp-N & 4609.1 & $4606.6( \pm 2)$ & $3451.4+1158.7$ \\
\hline 11 & DTNC $^{48}$ LSQSSTSKMAERC $^{62}{ }^{62}$ GKSEC C6 IVPASNFVFG $^{61}$ & Asp-N & 3452.5 & $3452.9( \pm 1.5)$ & \\
\hline 12 & $\begin{array}{l}\text { DALLQC }^{15} \\
\text { YSC }^{94} \mathrm{VQQQETISSIIC}^{106} \mathrm{EGS} \\
\text { DVC }^{135} \text { SIGRPHQQLK }\end{array}$ & TPCK trypsin/Asp-N & 4111.8 & $4113.6( \pm 2)$ & $3455+1480.9$ \\
\hline 13 & $\left.\left.\right|_{\text {YSC }} ^{\text {DALLQC VQQQETISSIIC }}\right|_{\text {DVC }^{106} \text { EGS SIGRPHQQLK }} ^{135}$ & TPCK trypsin/Asp-N & 4469.0 & $4469.9( \pm 2)$ & \\
\hline 14 & $\begin{array}{l}\text { QHDVC }^{35} \text { SIGRPDNQLTDTNC } \\
\text { SEC }^{68} \text { IVPASQSSTSK } \\
\text { IVADPC }\end{array}$ & TPCK trypsin (SA matrix) & 5164 & $5164( \pm 3)$ & 2933.9 \\
\hline 15 & 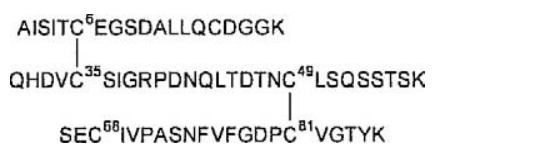 & TPCK trypsin (SA matrix) & 7042 & $7040( \pm 4)$ & 5164 \\
\hline
\end{tabular}

resented a protonated peptide with scrambled S-Sbond. The formation of this peptide is discussed further below.
For several disulfide bonds, diagnostic peaks from different enzyme digestions were obtained. For example, the disulfide bond between $C^{106}$ and $C^{135}$ was 
established from multiple peptide ions observed in the digests of immobilized TPCK trypsin/Asp-N and immobilized TPCK trypsin/Glu-C (see Supplemental Materials). From this digest, we were also able to identify the S-S-bond between $\mathrm{C}^{115}$ and $\mathrm{C}^{194}$ through the signal at $m / z 1893.5$ as previously published [23], and its ISD-fragment ion at $m / z$ 834.3.

In all analyzed peptide pools, it was interesting that often not both but only one of the two possible reduced ISD-fragments were observed. For example, entry 1 in Table 1 was observed as an abundant $[\mathrm{M}+\mathrm{H}]^{+}$signal at $m / z$ 2295.4. Two protonated ISD fragment ions, i.e., [DVC $^{35}$ SIGRPDNQLT $\left.+\mathrm{H}\right]^{+}$and $\left[\text {AISITC }{ }^{6} \text { EGS }+\mathrm{H}\right]^{+}$, were possible; however, only the former was observed abundantly at $\mathrm{m} / \mathrm{z} 1417.8$. This is consistent with the presence of a basic arginine (R). The other ISD fragment does not have a basic amino acid in its structure and, therefore, does not compete successfully for the proton. A similar trend was observed for entries 4-8, 10, 12. In the case of entry 10, both peptides contain $\mathrm{R}$ and $\mathrm{K}$, and both ISD-fragment ions were observed at $\mathrm{m} / \mathrm{z} 3451.4$ and 1158.7 , respectively.

The diagnostic peptide signals are summarized in Table 1 . Mass accuracy at low $m / z$ value was to within $0.5 \mathrm{~m} / \mathrm{z}$ for singly-charged ions. For ions with $\mathrm{m} / \mathrm{z}$ values between 5000 and 7000, the mass accuracy was to within 3-4 m/z. To unambiguously assign the disulfide bond of SEL24K, the disulfide bond-containing peptide ions were selected and submitted to the MS/MS fragmentation study (data not shown).

Overall, the disulfide bond pattern in SEL24K was established as shown in Figure 5. All cysteines are oxidized and the S-S-bond pattern is symmetrical across the tandem-repeat sequence, which is consistent with the related rhamnose-binding egg lectins from the Spanish mackerel [24, 25].

\section{Gas-Phase Scrambling of Disulfide Bonds in SEL24K}

When we investigated exclusively the tryptic peptides from SEL24K in CHCA matrix, some of the observed peptides had structures inconsistent with the S-Sbonds in the native protein as established above. The MALDI-TOF mass spectrum of the tryptic peptide pool displayed several abundant ionic species, the composi-
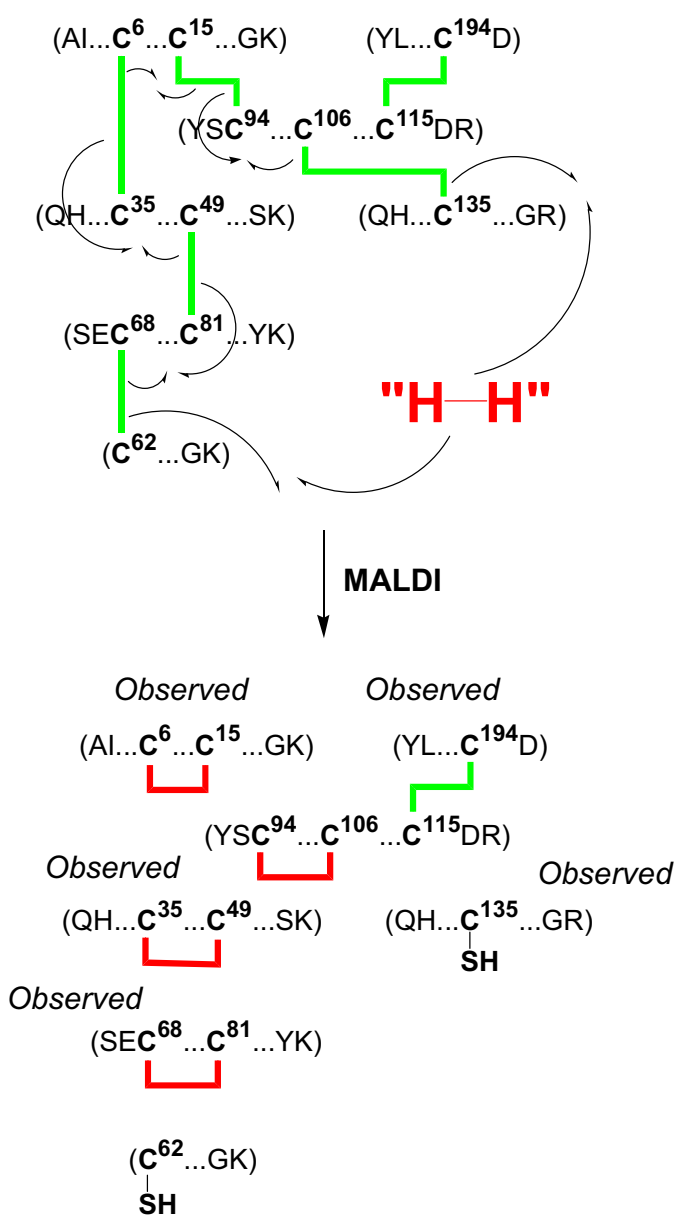

Scheme 2. Possible reaction mechanism for the laser-induced gas-phase scrambling of disulfide bonds in SEL24K.

tion of which could neither be established from in silico digestion of the fully reduced protein nor from conceivable S-S-bonded peptide strands. Subsequent MS/MS studies of those ions consequently caused us to derive their structures as shown in Scheme 2 [23].

The tryptic digestion of SEL24K leads to one particular disulfide-bonded peptide with six inter-chain S-Sbonds (only one missed tryptic cleavage site, i.e., $\mathrm{R}^{39}$ ) (Scheme 2). Concurrent transfer of one hydrogen atom each to $C^{62} / C^{135}$ during MALDI and subsequent disul-
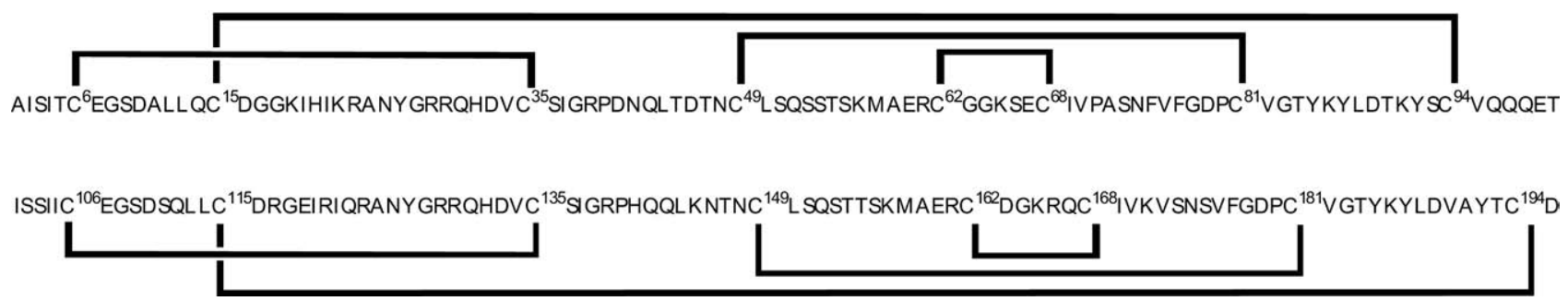

Figure 5. Disulfide bond pattern in SEL24K. All cysteines are oxidized and the S-S-bond pattern is symmetrical across the tandem-repeat sequence. 


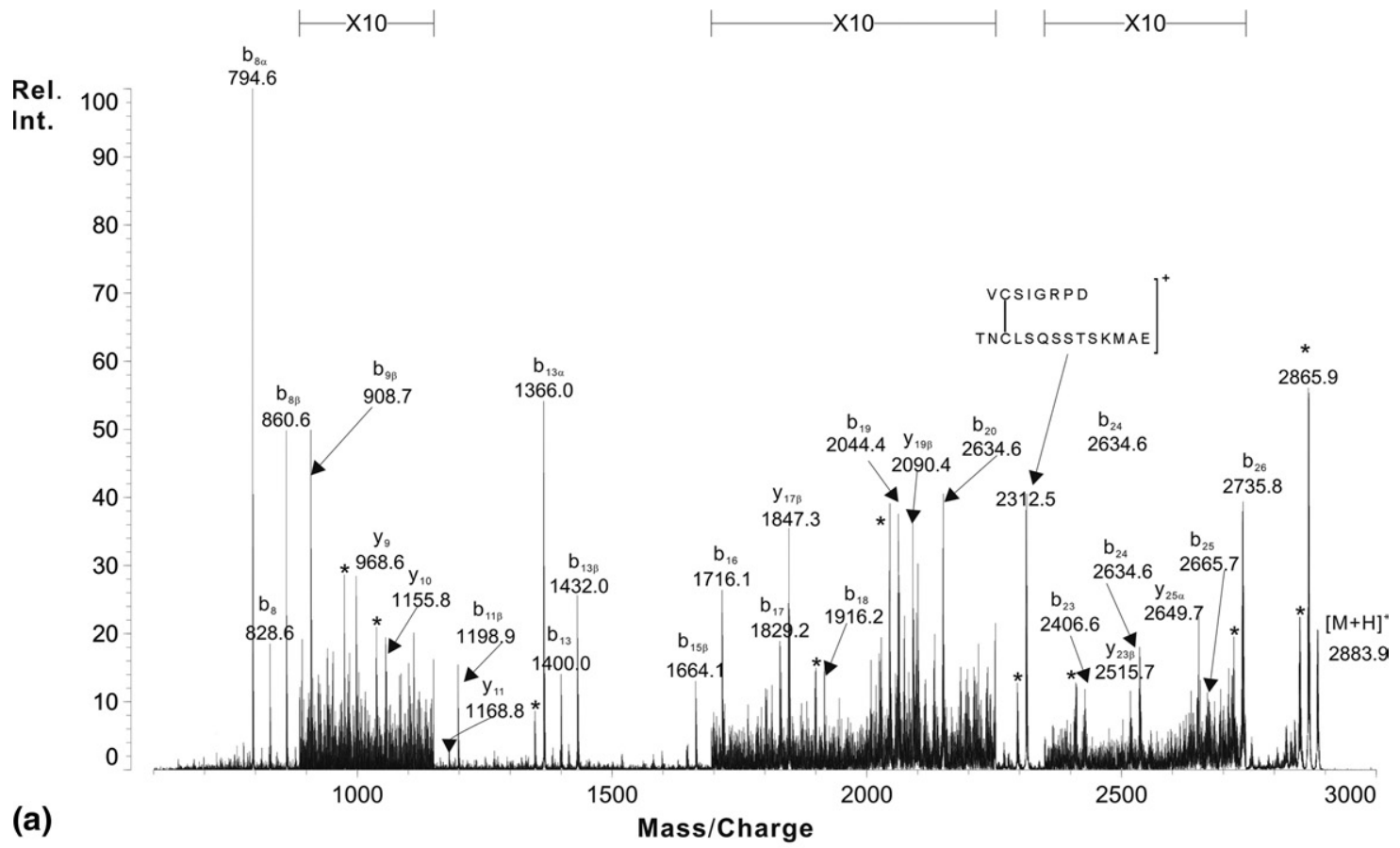

(a)

Mass/Charge

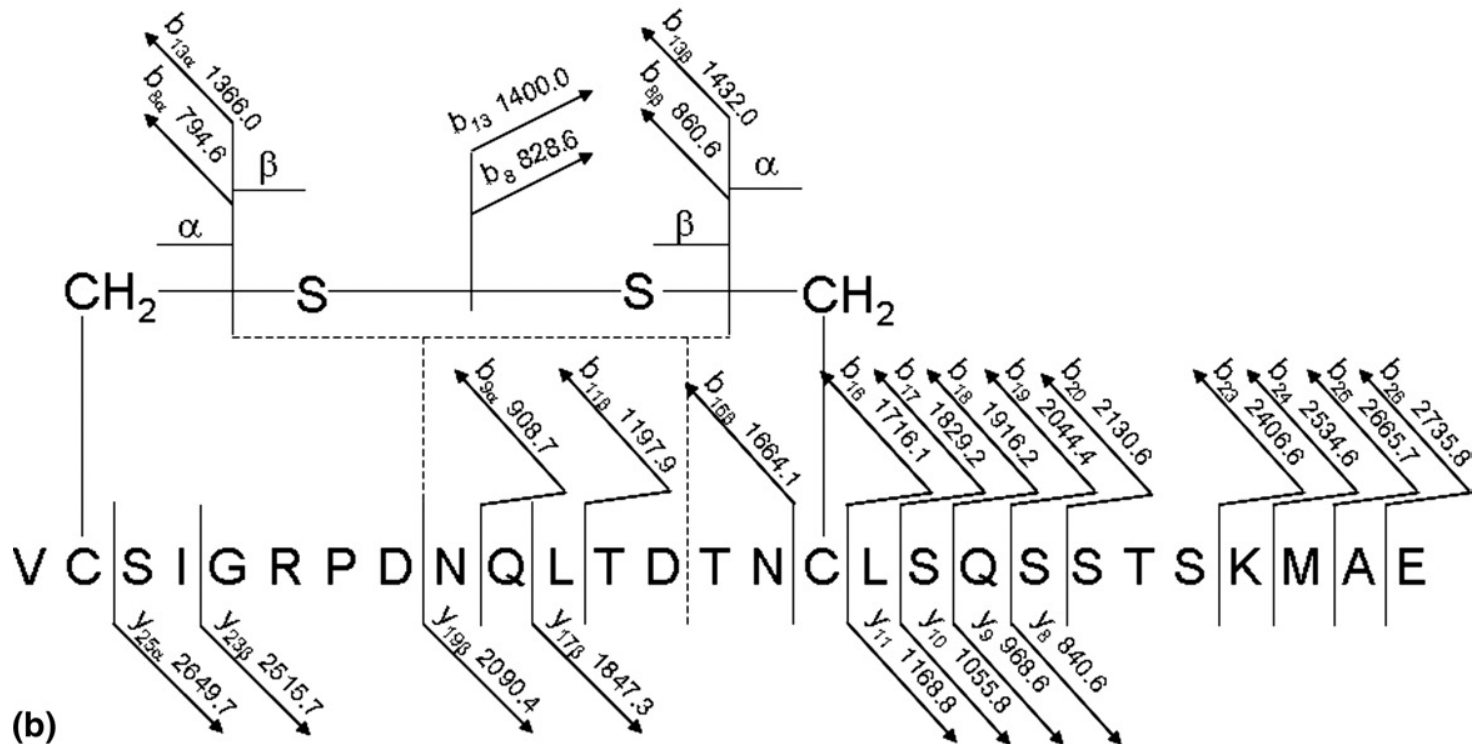

Figure 6. MS-data collected on the MALDI-QIT-TOF instrument. Peptides generated from SEL24K with Glu-C: (a) MS/MS spectrum of intrachain disulfide bond-containing peptide ion of $\mathrm{m} / \mathrm{z} 2883.7$ derived from the gas-phase scrambling. Internal losses are indicated by an asterisk. (b) Assignment of the MS/MS fragmentation of the ion from (a).

fide bond scrambling yields four new intra-chain S-Sbonds. All peptides formed in this way were detected as protonated molecules during MALDI-TOF analysis (Scheme 2).

Whereas peptides from Asp-N did not give rise to any scrambling during the desorption process (see Supplemental Materials), other enzymes and combinations thereof did. For example, the mass spectrum of peptides from the Glu-C digestion displayed a signal at $\mathrm{m} / \mathrm{z} 2883.7$. MS/MS-data allowed assignment of the peptide to the structure VC ${ }^{35}$ SIGRPDNQLTDTNC ${ }^{49}$ LSQSSTSKMAE
(34-60) with a scrambled intrachain disulfide bond (Figure 6) inconsistent with the above assignment of $\mathrm{Cys}^{6}-\mathrm{Cys}^{35}$ and $\mathrm{Cys}^{49}{ }^{4} \mathrm{Cys}^{81}$ (Figure 5).

Scheme 3 shows a possible mechanism for this scrambling. Initial fragmentation of the two disulfide bonds within fragment ion I was followed by formation of a new intrachain disulfide bond between $\mathrm{Cys}^{35}$ and $\mathrm{Cys}^{49}$, possibly supported by spatial disposition of the two sulfhydryl radicals. The remaining fragment ions II and IV are the result of reduction by the matrix $\mathrm{m} / \mathrm{z}$ 736.5, see Supplemental Materials). Unfortunately, frag- 

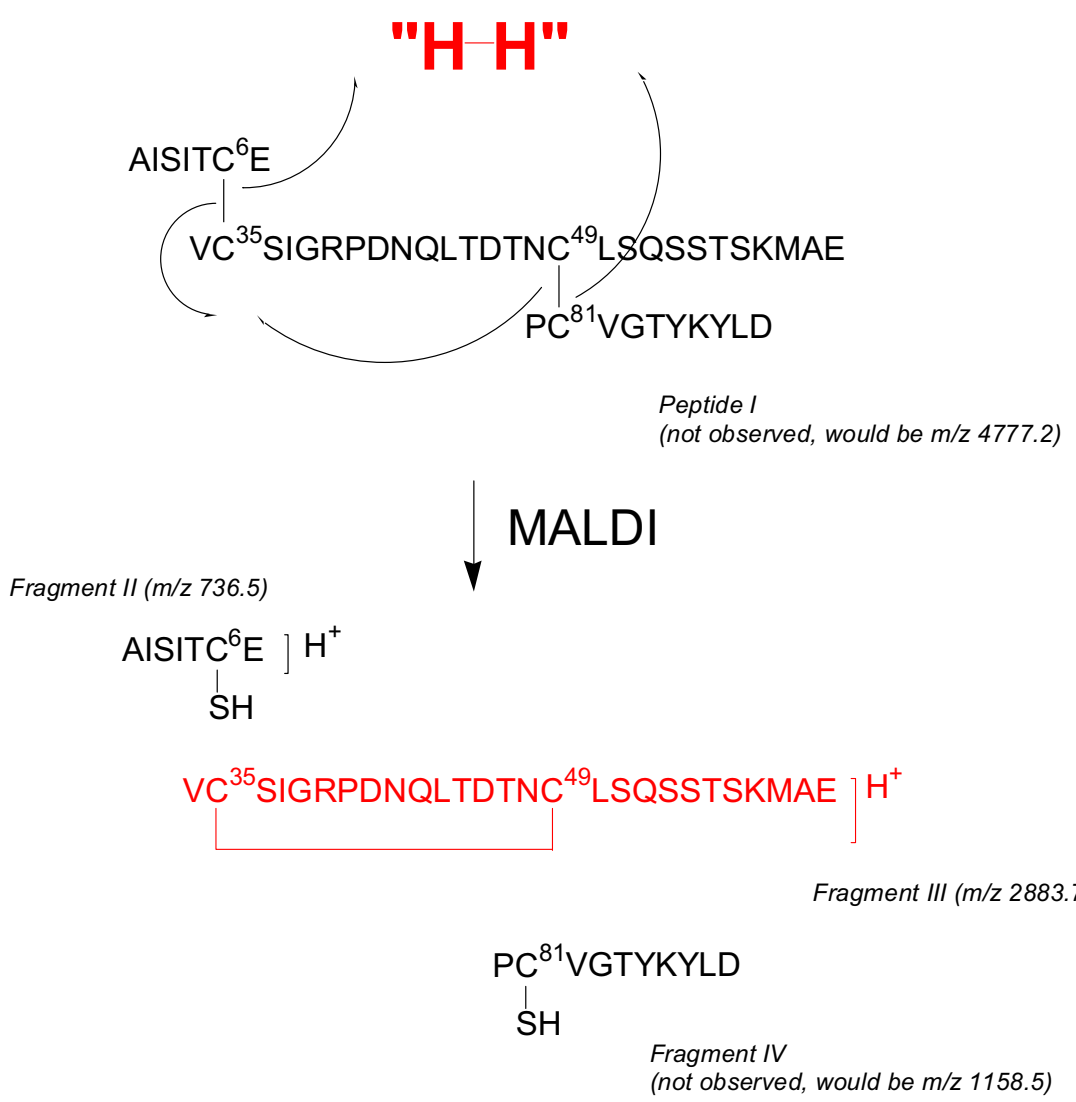
Scheme 3. Possible reaction mechanism for the photo-induced scrambling of disulfide bonds of a
peptide from the Glu-C digestion of SEL24K. A scrambled intrachain fragment ion and a reductive ISD
fragment ion were observed.

ment IV ion was not observed presumably because of ion suppression.

Also, the TPCK trypsin/ Asp-N enzyme combination resulted in scrambled peptides (data not shown). This possibly indicates that only specific peptides with favorable structural features, such as distance between cysteines and total number of cysteines in the peptide can lead to gas-phase S-S scrambling during MALDI.

That a photo-induced gas-phase S-S-bond rearrangement should occur at all as described above can be rationalized as follows. It is known that radicals can undergo very fast intramolecular rearrangement reactions, particularly if structural and spatial conditions are favorable [26]. The tendency of the polarizable sulfur atom to participate in radical reactions has been known for decades in many fields of chemistry [27-30]. It has been demonstrated that electron attachment to a disulfide bond leads to significant bond weakening and formation of stable radical species at low temperature in solution [31, 32]. The reduction of disulfide bonds by photoexcitation of tryptophan groups in goat $\alpha$-lactalbumin has been described before [33]. This process involves transfer of photo-electrons from a proximal tryptophan to the disulfide bond and subsequent cleavage into a thiolate ion and thiyl radical (see Supplemental Materials).
In the case of SEL24K, external matrix molecules produce photo-electrons upon UV laser excitation. Subsequent reactions presumably follow the mechanism described above. Unexpected peptides with scrambled disulfide bonds resulting from this process preferably may have an even number of cysteines (fully-paired because of proximity) displaying mainly intrachain bridges for thermodynamic reasons. All other peptides with an odd number of cysteines become subject to reduction (ISD). ISD is more commonly observed for interchain disulfide bonds than for intrachain disulfide bonds [34-36]. This indicates an inherently higher thermodynamic stability of intrachain S-S-bonds, and may provide a driving force for the scrambling reaction described above. Early evidence for this behavior was reported in electron ionization (EI)-MS-spectra of dithiacyloalkanes [37].

The tryptic peptide from insulin has an even number of disulfide bonds connecting both chains, and gives rise to radical recombination without reductive ISD. The tryptic peptide from SEL24K also has an even number of cysteines overall, but gives rise to scrambling with reductive ISD because of an odd number of cysteines in the chain, including $C^{135}$ and $C^{62}$. The absence of the complementary ISD fragment from the chain including $\mathrm{C}^{62}$ can be explained with ion- 
suppression because of absence of any basic amino acids in the peptide.

Finally, it is interesting to notice that in related rhamnose-binding lectins from the Spanish mackerel [24], peptides generated by trypsin have typically only one disulfide bond so that gas-phase scrambling is not of concern in this case, and ISD analysis remains a valuable analytical technique.

\section{Conclusion}

We have shown herein that tryptic peptides with multiple disulfide bonds have the potential for S-S-bond scrambling through a photo-induced radical recombination or through a radical redox reaction initiated by the matrix and ISD. Radical recombination scrambling may possibly be favored in cases of resulting peptides with fully-paired intrachain S-S-bridges, and matrix/ ISD-initiated radical redox scrambling may possibly be favored if chains with an odd number of cysteines are present. This phenomenon was observed not only for the tryptic peptide pool from SEL24K but also for the Glu-C digest. It was absent in the Asp-N digest. The coincidental distribution of cysteines and trypsin cleavage sites in SEL24K compared with other proteins gives rise to a macro-peptide with six disulfide bonds. As such, it represents a unique case and may not be representative generally. However, inadvertent mistakes in the assignment of disulfide bond patterns in proteins because of gas-phase scrambling can be avoided by using multiple enzymes and chemical modification. The disulfide bond pattern in SEL24K from the Chinook salmon Oncorhynchus tshawytscha was established unequivocally. Further experiments need to be carried out to fully elucidate the mechanism for the gas-phase disulfide bond scrambling reported herein.

\section{Acknowledgments}

The authors thank the Department of Chemistry for support and Dr. Kiran Morishetti for help with the electrospray measurements. They are grateful to Thermo-Fisher for access to the TSQ mass spectrometer. R.T.A. was supported by a University of California Dissertation Year Fellowship.

\section{Appendix A Supplementary Material}

Supplementary material associated with this article may be found in the online version at doi:10.1016/ j.jasms.2009.04.021.

\section{References}

1. Wu, J.; Watson, J. T. A novel methodology for assignment of disulfide bond pairings in proteins. Protein Sci. 1997, 6, 391-398.

2. Gallegos-Perez, J.-L.; Rangel-Ordonez, L.; Bowman, S. R.; Ngowe, C. O.; Watson, J. T. Study of primary amines for nucleophilic cleavage of cyanylated cystinyl proteins in disulfide mass mapping methodology. Anal. Biochem. 2005, 346, 311-319.
3. Wefing, S.; Schnaible, V.; Hoffmann, D. SearchXLinks. A Program for the Identification of Disulfide Bonds in Proteins from Mass Spectra. Anal. Chem. 2006, 78, 1235-1241.

4. Ryle, A. P.; Sanger, F. Disulfide interchange reactions. Biochem. J. 1955, $60,535-540$.

5. Bach, R. D.; Dmitrenko, O.; Thorpe, C. Mechanism of Thiolate-Disulfide Interchange Reactions in Biochemistry. J. Org. Chem. 2008, 73, 12-21.

6. Patterson, S. D.; Katta, V. Prompt fragmentation of disulfide-linked peptides during matrix-assisted laser desorption ionization mass spectrometry. Anal. Chem. 1994, 6621, 3727-3732.

7. Fukuyama, Y.; Iwamoto, S.; Tanaka, K. Rapid sequencing and disulfide mapping of peptides containing disulfide bonds by using 1,5-diaminonaphthalene as a reductive matrix. J. Mass Spectrom. 2006, 41, 191-201.

8. Yi, G.-S.; Cheong, C. Disulfide bond formation between the $N$-terminal region of P56LCK and the cytoplasmic domain of CD8 studied by electrospray ionization and matrix-assisted desorption/ionization timeof-flight mass spectrometry. Biochem. Mol. Biol. Int. 1996, 40, 409-416.

9. Gorman, J. J.; Ferguson, B. L.; Speelman, D.; Mills, J. Determination of the disulfide bond arrangement of human respiratory syncytial virus attachment $(\mathrm{G})$ protein by matrix-assisted laser desorption/ionization time-of-flight mass spectrometry. Protein Sci. 1997, 6, 1308-1315.

10. Cosenza, L.; Sweeney, E.; Murphy, J. R. Disulfide bond assignment in human interleukin-7 by matrix-assisted laser desorption/ionization mass spectroscopy and site-directed cysteine to serine mutational analysis. J. Biol. Chem. 1997, 272, 32995-33000.

11. Navale, V.; Kaushal, P.; Hunt, S.; Burducea, I.; Gentz, R.; Khan, F. Vertes, A. Peptide mapping and disulfide bond analysis of myeloid progenitor inhibitory chemokine and keratinocyte growth factor by matrix-assisted laser desorption ionization mass spectrometry. Anal. Biochem. 1999, 267, 125-134.

12. Watson, J. T.; Sparkman, O. D. Introduction to Mass Spectrometry, Instrumentation, Applications, and Strategies for Data Interpretation, 4th ed.; John Wiley and Sons: Hoboken, NJ, 2007; p 726-734

13. Lioe, H.; O'Hair, R. A. J. A Novel Salt Bridge Mechanism Highlights the Need for Nonmobile Proton Conditions to Promote Disulfide Bond Cleavage in Protonated Peptides Under Low-Energy Collisional Activation. J. Am. Soc. Mass Spectrom. 2007, 18, 1109-1123.

14. Fagerquist, C. K. Collision-activated cleavage of a peptide/antibiotic disulfide linkage: Possible evidence for intramolecular disulfide bond rearrangement upon collisional activation. Rapid Commun. Mass Spectrom. 2004, 18, 685-700.

15. Zhang, J.; Frankevich, V.; Knochenmuss, R.; Friess, S. D.; Zenobi, R. Reduction of $\mathrm{Cu}(\mathrm{II})$ in matrix-assisted laser desorption/ionization mass spectrometry. J. Am. Soc. Mass Spectrom. 2003, 14, 42-50.

16. Qiao, L.; Roussel, C.; Wan, J.; Kong, J.; Yang, P.; Girault, H. H.; Liu, B. MALDI in-source photo-oxidation reactions for online peptide tagging. Angew. Chem. Int. Edit. 2008, 47, 2646-2648.

17. Murata, K.; Fisher, A. J.; Hedrick, J. L. Crystallization and X-ray analysis of the salmon-egg lectin SEL24K. Acta Crystallogr. F 2007, F635, 396-398.

18. Zenner, B. D. The isolation and characterization of an egg lectin from king salmon, Oncorhynchus tshawytscha. Ph.D. Thesis, University of California, Davis, 1991

19. Becker, H. D. Photochemical reactions with phenols. VI. Photo+ sensitized reduction and addition reactions of quinoid compounds. J. Org. Chem. 1969, 34, 2472-2474.

20. Steenken, S.; Neta, P. One-electron redox potentials of phenols. Hydroxy- and aminophenols and related compounds of biological interest. J. Phys. Chem. 1982, 8618, 3661-3667.

21. De Kok, T. M. C. M.; Van Maanen, J. M. S.; Lankelma, J.; Ten Hoor, F.; Kleinjans, J. C. S. Electron spin resonance spectroscopy of oxygen radicals generated by synthetic fecapentaene-12 and reduction of FEC pentaene mutagenicity to Salmonella typhimurium by hydroxyl radical scavenging. Carcinogenesis 1992, 137, 1249-1255.

22. Mormann, M.; Eble, J.; Schwoeppe, C.; Mesters, R. M.; Berdel, W. E.; Peter-Katalinic, J.; Pohlentz, G. Fragmentation of intra-peptide and inter-peptide disulfide bonds of proteolytic peptides by nanoESI collision-induced dissociation. Anal. Bioanal. Chem. 2008, 3925, 831838.

23. Yu, H.; Murata, K.; Hedrick, J. L.; T. Almaraz, R.; Xiang, F.; Franz, A. H The Disulfide Bond Pattern of Salmon Egg Lectin 24K from the Chinook salmon Oncorhynchus tshawytscha. Arch. Biochem. Biophys. 2007, 463, $1-11$.

24. Terada, T.; Watanabe, Y.; Tateno, H.; Naganuma, T.; Ogawa, T.; Muramoto, K.; Kamiya, H. Structural Characterization of a RhamnoseBinding Glycoprotein (lectin) from Spanish Mackerel Scomberomorous niphonius eggs. Biochim. Biophys. Acta 2007, 17704, 617-629.

25. Tateno, H.; Ogawa, T.; Muramoto, K.; Kamiya, H.; Hirai, T.; Saneyoshi, M. A novel rhamnose-binding lectin family from eggs of steelhead trout Oncorhynchus mykiss with different structures and tissue distribution. Biosci. Biotechnol. Biochem. 2001, 65, 1328-1338.

26. Gorman, J. J.; Wallis, T. P.; Pitt, J. J. Protein disulfide bond determination by mass spectrometry. Mass Spectrom. Rev. 2002, 21, 183-216.

27. Gilbert, B. C. Structure and reaction mechanisms in sulfur-radical chemistry revealed by ESR spectroscopy. NATO ASI Series, Series A: Life Sciences. Sulfur-Cent. React. Intermed. Chem. Biol. 1990, 197, 135-154.

28. Russell, G. A.; Ngoviwatchai, P. Free radical processes in the reactions of organometallics with organic sulfur compounds. NATO ASI Series, Series A: Life Sciences. Sulfur-Cent. React. Intermed. Chem. Biol. 1990, 197, 291-302. 
29. Asmus, K. D. Stabilization of oxidized sulfur centers in organic sulfides. Radical cations and odd-electron sulfur-sulfur bonds. Acc. Chem. Res. 1979, 12, 436-442

30. Benson, S. W. Thermochemistry and kinetics of sulfur-containing molecules and radicals. Chem. Rev. 1978, 78, 23-35.

31. Hadley, J. H. Jr.; Gordy, W. Nuclear coupling of sulfur-33 and the nature of free radicals in irradiated crystals of N-acetyl-L-cysteine. Proc. Natl. Acad. Sci. U.S.A. 1977, 74, 216-220.

32. Hadley, J. H. Jr.; Gordy, W. Nuclear coupling of sulfur-33 and the nature of free radicals in irradiated crystals of cysteine hydrochloride and N-acetyl methionine. Proc. Natl. Acad. Sci. U.S.A. 1975, 72, 3486-3490.

33. Vanhooren, A.; Devreese, B.; Vanhee, K.; Van Beeumen, J.; Hanssens, I., Photoexcitation of tryptophan groups induces reduction of two disulfide bonds in goat $\alpha$-lactalbumin. Biochemistry 2002, 41, 11035-11043.
34. Kubwabo, C.; Vais, N.; Benoit, F. M. Characterization of microcystins using in-source collision-induced dissociation. Rapid Commun. Mass Spectrom. 2005, 19, 597-604.

35. Bure, C.; Le Falher, G.; Lange, C.; Delmas, A. Fragmentation study of peptide acetals and aldehydes using in-source collision-induced dissociation. J. Mass Spectrom. 2004, 39, 817-823.

36. Williams, J. D.; Flanagan, M.; Lopez, L.; Fischer, S.; Miller, L. A. D. Using accurate mass electrospray ionization-time-of-flight mass spectrometry with in-source collision-induced dissociation to sequence peptide mixtures. J. Chromatogr. A 2003, 1020, 11-26.

37. Musker, W. K.; Gorewit, B. V.; Roush, P. B.; Wolford, T. L. Formation of cyclic disulfide cation radicals in the electron impact induced fragmentation of mesocyclic dithioethers. J. Org. Chem. 1978, 43, 3235-3236. 